\title{
Research and Road Traffic
}

\section{By Mervyn O'Gorman, c.B.}

$\mathrm{V}^{\mathrm{A}}$ ARIOUS are the routes by which people attain the state of being 'firmly convinced' or 'absolutely sure' : some will have been at pains to assimilate a sufficiently cogent proof, others will have got there by accepting idly what is called 'common knowledge', others more easily still by reiterating sufficiently an unproved but specious assertion. Politically, all these convinced persons are important-notably the last groupfor reiteration is one of the instruments of politics. This group may be quite unaware of standing on weak ground but, on occasion, their subconscious recognition of futility is revealed by this token : that they are roused to a surprising anger by reasoned dissent, whereas the others can mostly entertain discussion, welcome a new viewpoint and derive pleasure from that valuable stimulus to thought-reasoned argument. The road traffic problem is one of multitudinous complexities but is so deceptively simple in appearance that assertions concerning its solution are rife, and strong convictions fortified only by 'it stands to reason' are almost universal. Everybody knows! This very universality would be convincing (such is another of the strange routes that lead us to our fixed judgments) were it not that a good few of us have a healthy suspicion of views upheld by imputing ill motives and supported by an indignation which, however well warranted at large, is directed with animus and without proof against some arbitrary mark.

It is into this matrix of somewhat unpromising public opinion that Sir Auckland Geddes, Dr. C. S. Myers and others-all too few-are instilling a selfquestioning doubt so that, one day (the sooner the better !), a public demand must arise for such scientifically guided experiment and research as shall reveal the true prime causes of road traffic troubles--and substitute knowledge for guesses and emphasis. Dr. Myers and the staff of the National Institute of Industrial Psychology, as well as Sir Auckland Geddes, probably have their private theories, and even their prejudices, on road questions, but their minds are sharp enough to cut through the emotional fringe. They perceive (1) that they in fact do not know, (2) that no one else knows. Hence their desire that the Government shall be instructed to appoint disinterested persons to find out by the only known method-the scientific one.

The modes of appeal to the public of Sir Auckland Geddes and Dr. Myers are, however, widely different. Sir Auckland, knowing that his English audience have nice, kind and (ashamedly) sentimental hearts, warms them by a picture for their souls' awakening. He writes: "this morning, I saw a fair-haired infant turned out with a 'kiddy-car' to play on an arterial road along which lorries, omnibuses and cars were passing in endless streams". Appealing to gentlemen, he selects a blonde!- - then he comes to business : "may we have an authoritative scientific inquiry to find out what we ought to do and avoid doing ..." on one hand, for road safety and, on the other, for "the fullest possible development of the manifold uses of the internal combustion engine applied to Road Transport" (Times, July 7). He gave piquancy to his appeal, for he preceded the sentence quoted with the words: "Now that Parliament has almost finished its labours on this subject . . " thus exposing the humour of thirty-three years of Parliamentary legislation in road matters, namely, preselecting the culprit, ordaining his punishment and then, perhaps, inquiring as to who might be responsible. In the circumstances he is right: better inquire late than not at all. It might turn out that the chief blame and responsibility for seven thousand deaths yearly on the road should fall on the triviality and ignorance of Parliament-albeit such home-truths -if true they be--should be stated very circumspectly by a wise committee of inquirers.

Having for years advocated this research, I observe that Sir Auckland Geddes' method of pleading is effective. I have had minor proofs. An appreciable number of persons have troubled to cut out his letter and post it to me! Some do so with approval, and one actually with angeras at a transparent attempt to delay by research the pleasing institution of extra punishments and speed limits which 'stand to reason'.

In the journal of the National Institute of Industrial Psychology, the Human Factor, for JulyAugust, Dr. C. S. Myers goes to work otherwise. $\mathrm{He}$ is not content with the mere advocacy of research. He does it. He leads by example. He has an organisation, and limiting himself to one subsection of the problem-the drivers-he has measured their speed of reaction, vision, vigilance, resistance to distraction, judgment of speed and size, etc. He and his staff do many of these tests in ingeniously simple ways, such that they cost little and can be applied to batches of eight persons. In this way, it appears, the time of the complete examination is shortened to about thirty minutes*. Having obtained groups of results and ascribed a tentative figure of merit to each man tested, he proceeds to standardise them, or rather to give to his laboratory observations a 'road user' value by comparing his figures of merit with those obtained from the records taken by the men's employers in relation to their previous and subsequent driving on the road.

It is good to hear that these selection tests have,

* The instrument by which a driver controls a dummy motor vehicle, while it appears to travel along a road, of which the image is projected on a cinema screen, is of wonderful ingenuity-but in my view, unless altered, this device is liable to mislead both examine and examinee, especially whenever the latter is acutely responsiv to the optical suggestion of an acceleration which fails to eventuate. In my own case I was made 'sea-sick' for some thirty-six hours afte fifteen minutes of the test and therefore, feeling ill, I certainly drove below my form--which happens to include no road casualties in the
last thirty years and only a trivial one in the six years preceding that. 
on trial, proved to be economically remunerative to certain employers of road vehicles. "Thus in Paris," Dr. Myers says, "whereas the frequency of accidents caused by taxis, private cars and lorries increased, between the years 1923 and 1932, by 145 per cent., the accident frequency caused by the omnibuses and trams of the General Transport Company of Paris since their use of selection tests during the same period decreased by 30 per cent." Thus we have an instance of how research on one single element (and not the biggest element) in road traffic movement can save life and money.

This kind of verification is admirable. I trust that we may expect this class of testing to become habitual with employer companies. It will incidentally accumulate information of great value to governments.

Equally admirable is Dr. Myers' scientifically inspired restraint. We learn that he resisted the quick enthusiasm of a certain politician who was swept along too fast by zeal for this excellent work. Dr. Myers adhered to his conviction-born of knowing his job-that to make such a test compulsory on all applicants as a condition for obtaining a driver's licence should not be yet. It is one thing to use it for what it was designed, namely, selecting the safer men among a firm's practised drivers, and quite another to use it to bar persons for ever from acquiring driving experience on the basis of a test calibrated in terms of practised drivers. Experto crede.

No form of test so far enforced by any foreign government for the granting of driving licences, and none that has been advocated for Great Britain within my knowledge, deserve other than the fervent opposition of pedestrians as well as motorists. They can do nothing for safety-they do not discover the cause of the driver's faultsnor are his really bad habits likely to appear until the inspector has left and his supervision been forgotten. Examination in the Road Code is good and should be enforced on all road users, else obedience to it cannot be relied upon. (This is because all road safety has for its basis the possibility for each traffic unit to know in advance what the other unit is to be expected to do : not necessarily by hand signals, but by always obeying a known code of conduct.) Nevertheless, the line of research represented by the work of the National Institute of Industrial Psychology is bound to develop if given the encouragement it deserves, and to produce that foundation of knowledge on which a really valuable scheme for licensing tests could eventually be based. Holding such views and such expectations, I feel that the achievements and studies of the Institute warrant a much more generous recognition by the Minister than a pat and a cheap cliché. He said, "He would certainly watch the future of these experiments with much interest .... !"

Instead of this detached and platonic watching, the Minister (who had just previously administered a bonne bouche of $£ 5,000$ to an organisation the function of which is to repeat 'take care' by poster and by preachment) should have given double this amount to an Institute which is doing the difficult thing : discovering 'how to take care'! In return for the subsidy the Government would no doubt stipulate for access to the information that is being and would be increasingly accumulated.

Be it noted that our information on what constitutes 'taking care', on how to 'take care', on who should 'take care' and when, and on how to provide that people shall be imbued with the instinctive reaction to 'take care' in the right way on the roads, is practically nil.

Let us see what the psychologist-dealing with a totally different class of accidents-those relating to the breakage of crockery in restaurants-has to say about this 'take care' business (see Human Factor, July-August).

"Before the importance and the complex nature of this 'human factor' were adequately recognized, factory accidents were attributed mainly to culpable 'carelessness', foolish recklessness, and to dangerous machinery" (p. 267). "The average man . . . is disposed to ascribe breakages, like all other accidents, to 'carelessness', and hence to regard punishment . . . as the most appropriate measure for their reduction. But 'carelessness' has no precise psychological significance, and punishment is now recognized educationally as an inadequate and often ineffective remedy for defective conduct. To allege carelessness, as the cause of an accident, merely implies the fallacy that if sufficient trouble or attention had been given, the accident would not have occurred. Both punishment and the notion of carelessness are merely excuses for not inquiring into the ultimate causes of defective behaviour" (p. 269).

It is remarkable that each word of this quotation as well as the conclusion, albeit a general statement on a widely different subject, applies closely to road accidents, and is an unconscious plea for scientific research on road matters. Moreover, it falls in with Sir Auckland Geddes' plea. The national, economic and social interests that depend on the proper fostering of the industry of road transport and transit require that it shall have a research section of scientific men. It is abundantly clear that to be fruitful this reference to research must on no account be confined to accidents but must be directed to illuminate us on the fullest possible safe development of the manifold beneficial uses of road transport.

It may here be remarked that, in road questions, fatalities-not accidents-are commonly invoked, because in other contexts, for example, railway accidents, a Board of Trade decision provides that casualties are not to be counted until they reach a certain standard of seriousness (such as incapacitation from work for a prescribed number of days). On the other hand, road casualties are to be all reported (since 1930), whether significant or not, under severe penalties. Hence the complete break in the curves of casualty statistics in 1930 - whereas the road fatalities give a curve. The introduction of the Road Code in 1930 (at the 
same time as the removal of speed limits) reduced the total of fatalities so greatly that despite the increases of vehicles and the increase of exposure in two abnormally fine weather years, the peak of fatalities in 1930 has not yet been touched again.

The scientific method would assuredly require us to relate the number of road fatalities in a place to the amount of traffic flow (pedestrian and other) there. It would establish at an early moment the machinery for measuring and recording increments of safe traffic flow--and thus would enable us to determine to what extent each alteration of, say, police control, or pedestrian behaviour, or of road layout, etc., conduced to it. It would quickly determine for us the vehicular spacing and speed which would give to a bridge or tunnel its maximum safe carrying power. It would restrain a Minister who desired to say he had "no concern with the accident ratio, but only with accidents", for it would cause him to realise the fatuousness of such a remark. It could not fail to observe that a year having an abnormally large number of fine, dry summer days (such as had not been known for thirty-eight years previously) must give rise to a manifold increase of the amount of exposure (that is, vehicle, pedestrian and bicyclist hours on the road). It would not allow this to be dismissed as irrelevant when imputing to an increase of misconduct a three or five per cent increase of road deaths during such a year. It would measure instead of guessing the relative merits of 'traffic lights' and 'roundabouts' for road crossings, respectively in town and country. It would follow up the psychological work needed to evolve safe instincts in the pedestrian and driver. It would not permit misleading statistical statements as to causation of accidents to appear unqualified by the necessary scientific reservations. It would bring the noise nuisance within the range of things measured, and therefore make it controllable without imperilling the industry. Street and vehicle illumination, so far as it affects drivers and walkers, as well as the dazzle problem, would come within its purview, and so would the evaluation in terms of accidents and in terms of cost of non-skid roads, lightcoloured road surfaces, proper sign-posting, and street naming-to give only a few examples.

A scientific inquiry would, in addition, lead us to the study of: the effect of alcohol or fatigue on the rapidity of drivers' and pedestrians' reactions, and the amount of slowing of reactions which may be significant. The true distribution of responsibility for causing vibration as between vehicle and road construction. The effect on road wear of various speeds-and of various weightsand of various intensities of pressure at the tyre. The economic advantages, or the reverse, of dispositions of traffic which are to-day left to speculation, the effect of trailers or, say, the values to be got from statistical knowledge of the average vehicle's circular journey in a town. The balance sheet of advantages, safety or road economy obtainable from providing for or prohibiting the standing of vehicles. There is no end to the list, for I realise as I am sketching out the services that a research committee could render that a full list would be tantamount to a statement of the essential knowledge which hitherto governments have neglected to obtain. In many instances they have even neglected to seek it.

In England,where, of thesixty-fourmillions sterling contributed by motorists alone, two thirds are taken away from the service of the road users' urgent needs, there is no warranty whatever for continuing on a course of parsimony which denies us the support of science and is paid for in the flesh and blood of the road users.

\section{Interactions of Gases and Ores during Iron Smelting}

$\mathrm{F}^{\mathrm{O}}$ $R$ some years past, under the auspices of the National Federation of Iron and Steel Manufacturers (now the British Iron and Steel Federation), an experimental inquiry has been carried out at the Imperial College of Science and Technology, London, under the direction of Prof. W. A. Bone, into the interactions of gases and ores during blast-furnace iron smelting. The results of this investigation have been embodied in a series of communications to the Iron and Steel Institute in 1927,1930 and papers read at its meeting in London on May 31 last. The latest report (Part 4) is of special interest in that it deals comprehensively with (1) equilibria in the systems $\mathrm{Fe}_{x} \mathrm{O}_{y}+y \mathrm{CO} \rightleftharpoons \mathrm{Fe}_{x} \mathrm{O}_{y-1}+y \mathrm{CO}_{2}$ between $750^{\circ}$ and $1150^{\circ}$ C., and $\mathrm{Fe}_{x} \mathrm{O}_{y}+y \mathrm{H}_{2} \rightleftharpoons \mathrm{Fe}_{x} \mathrm{O}_{y-1}+y \mathrm{H}_{2} \mathrm{O}$ between $450^{\circ}$ and $850^{\circ}$; and (2) the relative velocities of ore reduction by the carbonic oxide in blast-furnace gas over a temperature range of $450^{\circ}-1,000^{\circ}$ under the same conditions as regards gas speeds and composition as are met with in the blast-furnace itself.
While equilibria constants in the reversible reactions referred to are independent of the speed of the gas-stream involved, it has been found otherwise with both the absolute and relative velocities of ore reduction at a given temperature. One of the difficulties of the laboratory investigation has been the accurate determination of such velocities under the conditions of high gas speeds (up to $50 \mathrm{ft}$. per sec.) actually prevailing in blastfurnaces. This difficulty was, however, successfully surmounted, and the subsequent ore reduction velocity measurements were carried out at each of five selected temperatures $\left(450^{\circ}, 650^{\circ}, 750^{\circ}, 850^{\circ}\right.$ and $1000^{\circ}$ C.) and in each case at each of three gas speeds $(4,16$ and $48 \mathrm{ft}$. per sec.)-corresponding with slow, medium and fast rates of driving in the blast-furnace -in such a manner as enabled relative velocities to be determined precisely under these conditions, not only throughout the whole range of ore deoxidation up to 90 per cent completion, but also for every $\mathrm{CO}_{2}$-content of the blast-furnace 